\title{
Two-dose varicella vaccine effectiveness in China: a meta-analysis and evidence quality assessment
}

\author{
Zhujiazi Zhang, Luodan Suo, Jingbin Pan, Dan Zhao and Li Lu*
}

\begin{abstract}
Background: The objectives of this review were to evaluate the vaccine effectiveness (VE) of the two-dose varicella vaccine for healthy children in China and explore the application of the approach of Grades of Recommendation, Assessment, Development, and Evaluation (GRADE) in observational studies on VE.

Methods: We searched for observational studies on two-dose varicella VE for children in China aged 1-12 years that were published from 1997 to 2019, and assessed the quality of each study using the Newcastle Ottawa Scale (NOS). We used meta-analysis models to obtain the pooled two-dose VE, and the studies were divided into subgroups and analysed according to whether or not it was an outbreak investigation and its NOS score. The quality of evidence of VEs were rated by approach of the GRADE system.

Results: A total of 12 studies and 87,196 individuals were included. The pooled two-dose VE was 90\% (95\% confidence interval [Cl]: 69-97\%). The VE of outbreak studies (87\% [95\% Cl: 76-93\%]) was lower than non-outbreak studies (99\% [95\% Cl: 98-99\%]). There was no significant difference in VEs by different NOS quality. The quality of the evidence assessment of pooled two-dose VE was "low", which was rated down by one category in limitations and publication bias respectively and rated up by two category in large effect. The quality of evidence assessment in subgroup of NOS score $\geq 7$ was "moderate".

Conclusions: The VE of two-dose varicella vaccine is relatively high in preventing varicella, and is recommended for countries which need further control for varicella. However, higher quality evidence is needed as a supplement for stronger recommendations. The approach of GRADE could be applied for rating the quality of evidence in observational study.
\end{abstract}

Keywords: Varicella vaccine, Vaccine effectiveness, Meta-analysis, GRADE

\section{Background}

Varicella is a highly contagious disease caused by the Varicella-zoster virus (VZV), which is associated with fever and a generalized pruritic vesicular rash [1]. As varicella vaccines are available globally and introduced into the immunization program for children in some countries, morbidity and mortality associated with the disease has

\footnotetext{
*Correspondence: Iulibj@sina.com

Department of Immunization and Prevention, Beijing Center for Disease Prevention and Control, Beijing Research Center for Preventive Medicine, He Ping Li Zhong Jie No.16, Dongcheng District, Beijing 100013, China
}

been reduced successfully in recent years $[2,3]$. The first varicella vaccine (Varilrix) was introduced in China by GlaxoSmithKline Biologicals (Rixensart, Belgium) in 1997. However, it was not until the introduction of domestic vaccines in 2000 that varicella vaccines were widely used in China [4]. Most children were given one-dose schedule according to the instructions from the manufacturer. Although we succeeded in reducing varicella-related morbidity and mortality in the following years, it soon reached a stable level instead of continuously decreasing [5]. Varicella outbreaks still occurred frequently, especially in

C C The Author(s). 2021 Open Access This article is licensed under a Creative Commons Attribution 4.0 International License, which permits use, sharing, adaptation, distribution and reproduction in any medium or format, as long as you give appropriate credit to the original author(s) and the source, provide a link to the Creative Commons licence, and indicate if changes were made. The images or other third party material in this article are included in the article's Creative Commons licence, unless indicated otherwise in a credit line to the material. If material is not included in the article's Creative Commons licence and your intended use is not permitted by statutory regulation or exceeds the permitted use, you will need to obtain permission directly from the copyright holder. To view a copy of this licence, visit http://creativecommons.org/licenses/by/4.0/ The Creative Commons Public Domain Dedication waiver (http://creativecommons.org/publicdomain/zero/1.0/) applies to the data made available in this article, unless otherwise stated in a credit line to the data. 
schools and kindergartens with a coverage rate of nearly $100 \%[6-8]$.

Since 2012, two-dose schedule started to recommend in some districts of China for further control of the outbreaks and the prevalent of varicella [9]. As a result, the coverage rate of the varicella vaccine has generally improved, with a one-dose coverage rate of $80-93 \%$ and a two-dose coverage rate of $48.7-72.9 \%$ [10-12]. The schedule transformation also provided a field to access the vaccine effectiveness (VE) of the two-dose vaccine, some studies confirming that the VE of the two-dose vaccine is indeed significant different from that of the one-dose vaccine. However, the sample sizes of those studies were usually insufficient and the outcomes were not always the same $[6,13,14]$. Therefore, we conducted a systematic literature review and meta-analysis to assess a more authentic effectiveness of the two-dose vaccine and provide more evidence for adjusting varicella immunization strategies at the national level.

The approach of Grades of Recommendation, Assessment, Development, and Evaluation (GRADE) was proposed to rate the quality of evidence and grading strength of recommendations by the GRADE Working Group in 2004 [15]. This has been adopted by 28 international organizations, such as the World Health Organization and the Cochrane Collaboration. the framework offers a transparent and structured process for developing and presenting evidence summaries for systematic reviews and guidelines in health care and carrying out the steps involved in developing recommendations [16]. However, at the time of writing, experience with GRADE has only been used for the evaluation of therapeutic interventions research and clinical questions rather than for public health and health systems questions $[17,18]$; thus, there was limited experience for reference. In this study, the approach of GRADE was applied to assess the quality of evidence provided by observational studies on VE evaluation in order to provide a new train of thought and reference for other researchers.

\section{Methods}

\section{Inclusion criteria}

The Inclusion criteria were as follows: 1) observational study on two-dose varicella VE; 2 ) the study population was healthy Chinese children aged 1-12 years old; 3 ) the intervention was immunization with two doses of the varicella vaccine; 4) the comparison was no immunization with the varicella vaccine; and 5) the outcome was VE in the studied population. Studies on clinical trials, methodology, molecular biology, vaccine development, animal studies, popular science lectures, newspaper articles, and literature reviews were excluded.
For articles that were published repeatedly, we selected the one with most complete information.

\section{Search strategy}

We searched for articles published from 1997, when the first varicella vaccine was introduced into China, to September 2019, in the following databases: China National Knowledge Internet, Wan Fang Database, Chinese Biomedical Literature Service System (SinoMed), PubMed, EMBASE, and Cochrane Library. We used search terms including "varicella", "chickenpox", "vaccine", "effective", "effectiveness", and "protective". "Chinese" or "China" were used when searching for English articles to identify articles that presented data on varicella VE in the Chinese population. Reference lists of selected articles and key published reviews [19-21] were also hand-searched (Supplementary file 1). This systematic review and metaanalysis was performed according to the Preferred Reporting Items for Systematic Reviews and MetaAnalyses (PRISMA) protocol [22].

\section{Study selection}

We used NoteExpress (3.2.0.7629) to eliminate duplicates. Two reviewers (ZZ and LS) screened the studies based on the inclusion criteria described above independently. Disagreements were resolved by consensus or consultation with a third member of the team (LL).

\section{Data extraction}

Data extraction forms were developed for the methodological quality assessment of individual studies, subanalysis, and evidence quality rating. Two reviewers (ZZ and LS) performed the data extraction independently. Authors of original articles were contacted in the event of missing or inaccurate information. The VE was calculated by the reviewers when it was not reported but there were enough data to estimate.

For each included study in analysis, we abstracted information on the characteristics of the study (authors, study year, study design and analysis, cases and information sources, and conflicts of interest), population, intervention (vaccination status, vaccine type, age at vaccination, number of doses, and interval between doses), and outcome (case definition, diagnosis and reporting, observation duration, and loss to follow-up). VE was calculated by comparing varicella attack rates among vaccinated and non-vaccinated populations or by comparing the vaccination status of cases and non-cases during varicella outbreaks $[23,24]$.

\section{Methodological quality assessment}

Two reviewers (ZZ and LS) independently evaluated the methodological quality for included studies, and any disagreements were resolved by consensus or by consulting 
a third member of the team (LL). The Newcastle-Ottawa Scale (NOS) $[25,26]$ was adapted to evaluate the selection, comparability, and outcome/exposure of the study, using eight items for case-control studies and cohort studies. A maximum of nine points was assigned to each study. Studies with a score of 1-3, 4-6, or 7-9 was considered as being of "low", "intermediate", or "high" methodological quality, respectively.

\section{Meta-analysis}

We used Stata (version 15.0) to perform all statistical calculations in this meta-analysis. Data were combined and estimated for a pooled relative risk (RR) or odds ratio (OR), depending on the study design, and 95\% confidence intervals (CIs) were calculated. The RRs/ORs and CIs of the subgroups were analysed by a outbreak or non-outbreak investigation and NOS score. VE was calculated as $(1-\mathrm{RR} / \mathrm{OR}) \times 100 \%$. The $I^{2}$ value was used to assess heterogeneity [27]. We considered $I^{2} \geq 50$ as being of high heterogeneity and chose random effects models, and $I^{2}<50$ as being of low heterogeneity and chose fixed effects models. Publication bias was assessed using Egger's regression test; $P<0.05$ indicates evidence of publication bias.

\section{Evidence quality rating}

We used GRADEpro (version 3.5) to rate the quality of evidence of VEs by means of the GRADE system; the ratings were completed by two reviewers ( $\mathrm{ZZ}$ and LS) and any disagreements were resolved by consulting a third member of the team (LL). The quality of evidence was divided into four categories: "high", "moderate", "low", and "very low". This was to reflect our confidence that the estimated of the VEs were correct. Randomized trials were considered high quality evidence, and observational studies as low quality. Five factors can decrease the quality of evidence: limitations, inconsistency, indirectness, imprecision, and publication bias. Three factors can increase the quality of evidence: large effect, plausible residual confounding, and dose-response gradi [28].

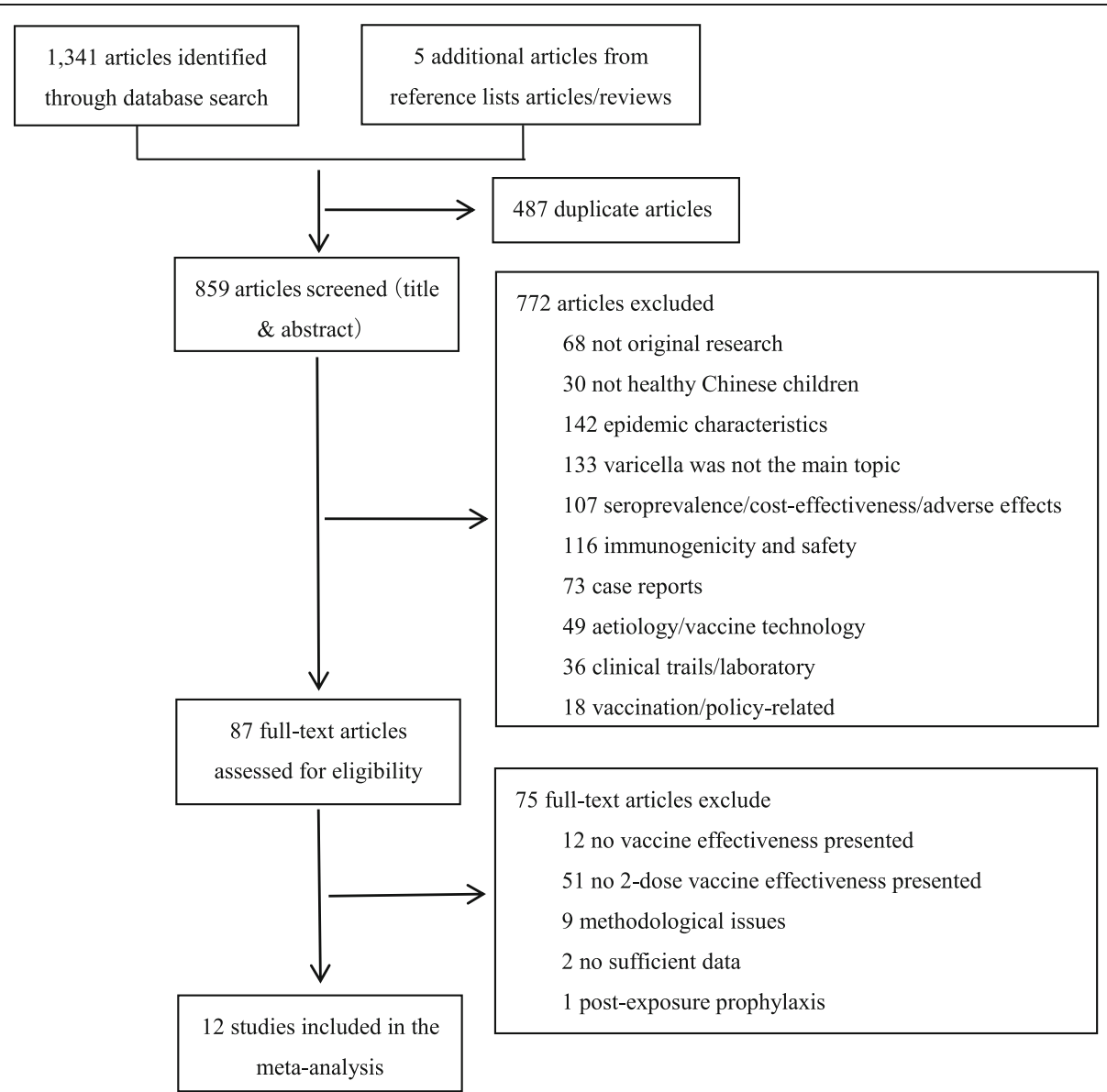

Fig. 1 Study selection: Two reviewers selected the studies independently according to the Preferred Reporting Items for Systematic reviews and Meta-Analyses (PRISMA). Any disagreements were resolved by consulting the third person 


\section{Results}

\section{Search results}

We identified a total of 1341 articles from the literature search and five extra articles; 487 duplicate articles were excluded. After reviewing titles and abstracts, 772 articles were found to not be original research, or were on other topics or had different populations. Of the remaining 87 articles, we read the full-text and found that most were not on two-dose VE or even general VE. We also excluded articles that did not provide correct and sufficient data. Finally, 12 original studies met our inclusion criteria for meta-analysis (Fig. 1; references listed in Table 1) [6, 13, 14, 29-37].

\section{Study characteristics}

We included 12 studies on two-dose varicella VE which were all cohort studies. Of these, 10 studies were conducted during outbreak investigations and used a retrospective cohort study design, one used a retrospective cohort design based on data from the Information System of disease and immunization, and one used a prospective cohort based on community investigation. The population studied mainly included children in settings of elementary schools (10 out of 12) whose ages ranged from 5 to 12 years old; two additional studies were on local children from the community. A total of 87,196 individuals were included and the overall age range was from 2 to 12 years (Table 1 ).

\section{Methodological quality of study}

According to the NOS, the overall median quality score was 6.6 (4-8). Nine studies (75\%) scored above 7, which indicated high quality, while the other three studies (25\%) scored 4-6, indicating intermediate quality (Table $1)$. The main reasons for a lower score were as follows: 10 studies had a poor representativeness of cohorts, two studies likely had selection bias of the individuals, 10 studies could not ensure the comparability of cohorts, three studies had no confirmed outcome records, and one study did not have a sufficient follow-up duration.

\section{Meta-analysis of 2-dose varicella vaccine effectiveness}

The meta-analysis of the 12 studies showed there was statistically significant heterogeneity $\left(I^{2}=83 \%\right)$; thus, pooled estimates of RR were calculated using a random effects model. The pooled two-dose VE for the prevention of varicella was $90 \%$ (95\% CI: 69-97\%; Fig. 2). There was evidence of publication bias indicated by Egger's regression test ( $p=0.024$; Fig. 3 ). If one study with a large

Table 1 Basic information of studies included in this meta-analysis

\begin{tabular}{|c|c|c|c|c|c|c|c|c|c|}
\hline Author & $\begin{array}{l}\text { Study } \\
\text { Year }\end{array}$ & $\begin{array}{l}\text { Study } \\
\text { Design }\end{array}$ & $\begin{array}{l}\text { Study Setting, Range of } \\
\text { Age/Average Age }\end{array}$ & Participants & $\begin{array}{l}\text { Outbreak } \\
\text { or Not }\end{array}$ & Selection $^{b}$ & Comparability $^{\mathbf{b}}$ & Outcome $^{b}$ & $\begin{array}{l}\text { Total } \\
\text { Score }^{b}\end{array}$ \\
\hline Li Lu & 2012 & $\begin{array}{l}\text { Retrospective } \\
\text { cohort }\end{array}$ & Elementary school, 5-8 y & 8 & Y & 3 & 2 & 3 & 8 \\
\hline $\begin{array}{l}\text { Pang } \\
\text { Hong }\end{array}$ & $\begin{array}{l}2011- \\
2012\end{array}$ & $\begin{array}{l}\text { Retrospective } \\
\text { cohort }\end{array}$ & Elementary school, 6-12 y & 123 & Y & 3 & 1 & 3 & 7 \\
\hline Sui Haitian & 2015 & $\begin{array}{l}\text { Retrospective } \\
\text { cohort }\end{array}$ & Elementary school, 6-12 y & 234 & Y & 1 & 1 & 2 & 4 \\
\hline Zhu Qi & $\begin{array}{l}2014- \\
2015\end{array}$ & $\begin{array}{l}\text { Retrospective } \\
\text { cohort }\end{array}$ & $\begin{array}{l}\text { Kindergarten and elementary } \\
\text { school, 5-10 } \mathrm{y}^{\mathrm{a}}\end{array}$ & 325 & $Y$ & 3 & 1 & 3 & 7 \\
\hline Wei Yujia & 2015 & $\begin{array}{l}\text { Retrospective } \\
\text { cohort }\end{array}$ & Elementary school, 8 y & 65 & Y & 3 & 1 & 3 & 7 \\
\hline $\begin{array}{l}\text { Xingqiang } \\
\text { Pan }\end{array}$ & $\begin{array}{l}2009- \\
2016\end{array}$ & $\begin{array}{l}\text { Retrospective } \\
\text { cohort }\end{array}$ & Community, 3-8 $\mathrm{y}^{\mathrm{a}}$ & 83,481 & $\mathrm{~N}$ & 4 & 0 & 3 & 7 \\
\hline Sun Yuan & 2016 & $\begin{array}{l}\text { Retrospective } \\
\text { cohort }\end{array}$ & Elementary school, 7-12 y & 817 & Y & 3 & 1 & 3 & 7 \\
\hline Wang Xu & 2016 & $\begin{array}{l}\text { Retrospective } \\
\text { cohort }\end{array}$ & Elementary school, 9-12 y & 763 & Y & 3 & 1 & 3 & 7 \\
\hline $\begin{array}{l}\text { Cai } \\
\text { Jintang }\end{array}$ & $\begin{array}{l}2015- \\
2016\end{array}$ & $\begin{array}{l}\text { Prospective } \\
\text { cohort }\end{array}$ & Community, 2-6 y & 79 & N & 3 & 2 & 1 & 6 \\
\hline $\begin{array}{l}\text { Chen } \\
\text { Jinsheng }\end{array}$ & 2017 & $\begin{array}{l}\text { Retrospective } \\
\text { cohort }\end{array}$ & Elementary school, 6-12 y & 569 & Y & 3 & 1 & 3 & 7 \\
\hline $\begin{array}{l}\mathrm{Ni} \\
\text { Zhaorong }\end{array}$ & $\begin{array}{l}2017- \\
2018\end{array}$ & $\begin{array}{l}\text { Retrospective } \\
\text { cohort }\end{array}$ & Elementary school, 6-12 y & 516 & Y & 2 & 1 & 2 & 5 \\
\hline $\begin{array}{l}\text { Zhuang } \\
\text { Lin }\end{array}$ & 2018 & $\begin{array}{l}\text { Retrospective } \\
\text { cohort }\end{array}$ & Elementary school, 6-11 y & 216 & Y & 3 & 1 & 3 & 7 \\
\hline
\end{tabular}

${ }^{\mathrm{a}}$ Our estimate; age range not provided in the publication

belection (maximum:four stars); Comparability (maximum:two stars); Outcome (maximum:three stars); Total score (maximum:nine stars) 


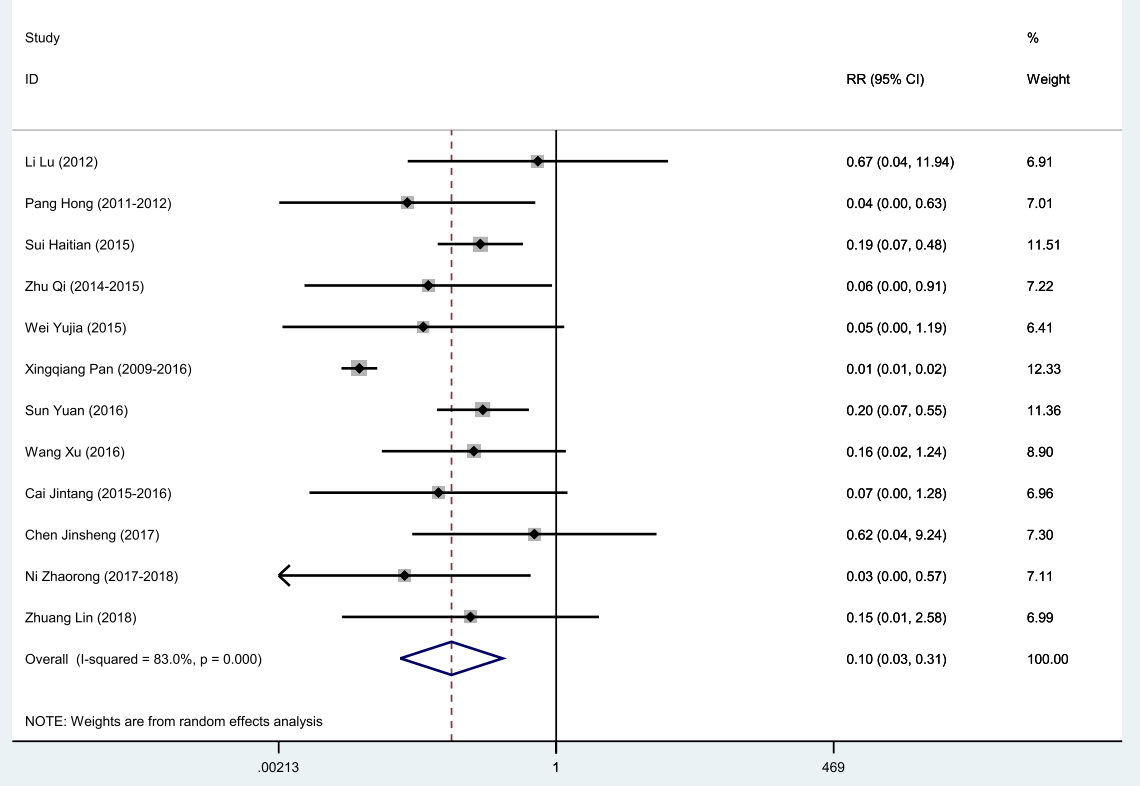

Fig. 2 Random effects model of two-dose varicella VE for prevention varicella

sample size $(83,481)$ was removed [33], the pooled twodose VE was $87 \%$ (95\% CI: $77-93 \%, I^{2}=0$ ).

The studies were divided into subgroups and analysed according to whether or not it was an outbreak investigation and its NOS score. The heterogeneity of the studies with an NOS score of $\geq 7$ was significant; therefore, we conducted a random effect model. The heterogeneity of other subgroups was less significant, and so fixed effect models were used. The polled two-dose VE of outbreak investigations was 87\% (95\% CI: 76-93\%). This was lower than that of non-outbreak investigations, which was 99\% (95\% CI: 98-99\%). Pooled VE estimates were similar in terms of the NOS score, which was $90 \%$ (95\% CI: 60-97\%) for scores $\geq 7$ and $88 \%$ (95\% CI: $71-$ $95 \%$ ) for scores $<7$ (Table 2). Only one study [36] explained the vaccine type, a domestic vaccine produced by Beijing Tiantan biological products corporation limited, whose VE was 93\% (95\% CI across the invalid line).

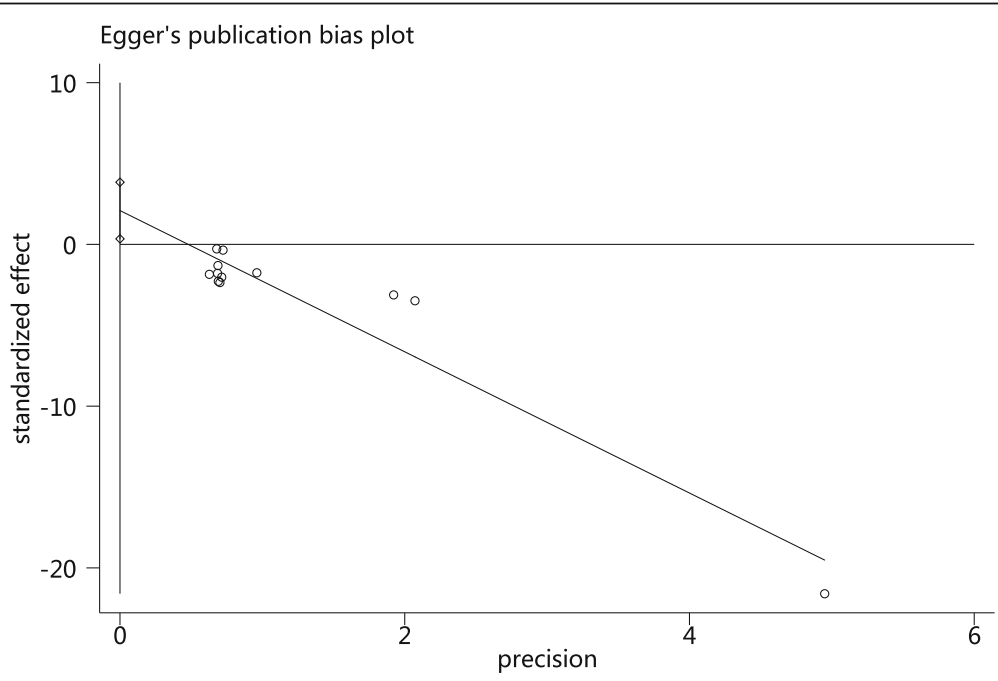

Fig. 3 Funnel plot of two-dose varicella VE for prevention varicella 
Table 2 Results of two-dose varicella VEs analysis

\begin{tabular}{clllllll}
\hline Subgroup & No. of Study & Individuals of Study & $\boldsymbol{I}^{\mathbf{2}}$ (\%) & Polling Model & Publication Bias & RR (95\%Cl) & VE (\%, 95\%Cl) \\
\hline $\begin{array}{l}\text { Overall } \\
\text { Outbreak }\end{array}$ & 12 & 87,196 & 83 & Random & 0.024 & $0.10(0.03 \sim 0.31)$ & $90(69 \sim 97)$ \\
$\quad$ Y & 10 & 3636 & 0 & Fixed & 0.334 & $0.13(0.07 \sim 0.24)$ & $87(76 \sim 93)$ \\
N & 2 & 83,560 & 34 & Fixed & 0.001 & $0.01(0.01 \sim 0.02)$ & $99(98 \sim 99)$ \\
NOS score & & & & & $0.10(0.03 \sim 0.40)$ & $90(60 \sim 97)$ \\
$\geq 7$ & 9 & 86,367 & 82 & Random & 0.020 & $0.12(0.05 \sim 0.29)$ & $88(71 \sim 95)$ \\
\hline 7 & 3 & 829 & 0 & Fixed & 0.208 & &
\end{tabular}

The quality of evidence assessment in GRADE framework The outcome of our evidence quality assessment was clinically diagnosed varicella, whose importance was rated crucial (8 points). Because all of the included studies were observational studies, the initial quality of the evidence was "low". Overall, the evidence quality assessment of the polled two-dose VE was "low". Limitations was rated down by one category as selection bias of the study populations was likely present. Inconsistency was not rated down as we were sure the reason of the significant heterogeneity was a study [33] that had a large sample size and higher RR. Indirectness was not rated down as the population, intervention, comparison and outcomes of the studies were consistent with what we studied in this meta-analysis. Imprecision was not rated down as the sample size of our study was relatively sufficient and the CI was moderate and did not cross the invalid line. Publication bias was rated down by one category as the Egger's regression test indicated an evidence of publication bias. Large effect was rated up by two categories for a very large association of $R R(<0.2)$.

The quality of evidence assessment of the polled VEs of the subgroups showed that it was "moderate" in subgroups with an NOS score of $\geq 7$ but "low" in other subgroups (Table 3).

\section{Discussion \\ Meta-analysis}

This study systematically assessed the effectiveness of two-dose varicella vaccines used in China in a GRADE frame. In our analysis that included around 90,000 Chinese children from 12 studies, the two-dose varicella vaccine VE was $90 \%$, similar to another global study (92\%) [38]. Compared with the one-dose varicella vaccine VE (75\%) [39] we studied previously, two doses of the vaccine could provide an extra $15 \%$ of protection than the one-dose. Compared with other vaccines, the two-dose varicella vaccine was shown to provide higher protection than the influenza vaccine (the VEs of different subtypes were approximately 33-73\%) [40] and the two-dose rotavirus vaccine $(63-72 \%)$ [41], and is similar with the measles vaccine (one dose was 90-95\%) [42] and the measles-mumps-rubella vaccine $(92 \%$ against measles [43] and 89\% against rubella [44]). These means that the $\mathrm{VE}$ of the two-dose varicella vaccine is relatively high.

Table 3 The summary of rating quality of evidence for two-dose varicella VEs

\begin{tabular}{|c|c|c|c|c|c|c|c|c|c|}
\hline & \multicolumn{5}{|c|}{ Evidence Decrease } & \multicolumn{3}{|c|}{ Evidence Increase } & \multirow[t]{2}{*}{ Quality } \\
\hline & limitations & Inconsistency & Indirectness & Imprecision & $\begin{array}{l}\text { Publication } \\
\text { Bias }\end{array}$ & $\begin{array}{l}\text { large } \\
\text { Effect }\end{array}$ & $\begin{array}{l}\text { Plausible } \\
\text { Confounding }\end{array}$ & $\begin{array}{l}\text { Dose-response } \\
\text { Gradi }\end{array}$ & \\
\hline $\begin{array}{l}\text { Pooled } \\
\text { VE }\end{array}$ & serious $^{a}$ & $\mathrm{no}^{\mathrm{b}}$ & no & no & serious $^{c}$ & $\begin{array}{l}\text { very } \\
\text { large }^{d}\end{array}$ & no & no & LOW \\
\hline \multicolumn{10}{|c|}{ Outbreak } \\
\hline$Y$ & serious $^{a}$ & no & no & no & no & large $^{d}$ & no & no & LOW \\
\hline $\mathrm{N}$ & serious $^{a}$ & no & no & no & serious $^{c}$ & $\begin{array}{l}\text { very } \\
\text { large }^{d}\end{array}$ & no & no & LOW \\
\hline \multicolumn{10}{|c|}{ NOS score } \\
\hline$\geq 7$ & no & no ${ }^{b}$ & no & no & serious $^{c}$ & $\begin{array}{l}\text { very } \\
\text { large }^{d}\end{array}$ & no & no & MODERATE \\
\hline$<7$ & serious $^{a}$ & no & no & no & no & large $^{d}$ & no & no & LOW \\
\hline
\end{tabular}

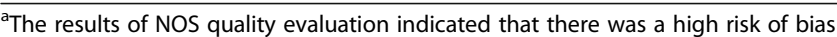

${ }^{b}$ We were sure the reason of the significant heterogeneity was a study had a large sample size and higher RR compared to the other studies

'Egger's regression test indicated an evidence of publication bias

${ }^{d}$ We rated quality of evidence up by one category for RR associations less than 0.2 , and up by two categories for associations less than 0.1 
In China, only a few provinces have proposed a twodose varicella vaccine recommendation as a nonexpanded programme on immunization vaccine for Chinese children. Beijing was the first province that implemented a two-dose immunization strategy in 2012 [9], with the two-dose vaccine coverage reaching approximately $30-70 \%$ for different paediatric age groups in the following years [10]. At the same time, a significant decline of the varicella outbreak $(52.7 \%$ [45]) was observed in the school setting, with the cases and the duration of the outbreaks decreasing as well. Thus, the two-dose varicella vaccine immunization strategy should be considered for children of the appropriate age in China as well as in other countries or areas that want improved control of varicella. Therefore, more studies and data are needed to confirm our results strongly.

The point estimate of the pooled VE of the outbreak was relatively lower than that of non-outbreak $(87 \%$ versus $99 \%$ ), which were similar to other outbreak and nonoutbreak VE studies, respectively [46, 47]. There are no definitive explanations for this low effectiveness; it has been speculated that the force of infection may be high in some outbreaks or the degree of exposure may vary among study subjects. Decreased VE and failure of the vaccine to take effect could also be a reason for the outbreak-like breakthrough of varicella after the administration of a one-dose varicella vaccine [38]. Another reason may be that the studies with a large study population are more likely to attract researchers' attention and be published [48].

\section{Evidence quality assessment}

Through our assessment, the GRADE rating results of the evidence quality of two-dose varicella vaccine VE was "low", which meant that our confidence in this VE estimate was limited and the true effectiveness may be substantially different from the estimated effectiveness. The main reasons of the quality decrease were as follows: 1) evidence from observational studies are generally initially "low". All of the studies included in this meta-analysis were observational; most observational studies, even well-implemented ones, generally receive a quality evidence rating of "low" [49]; 2) there may be a high risk of bias. The NOS score range was $4-8$, which indicated there were methodological defects in some studies; for instance, the individuals of most of the studies were recruited from an outbreak investigation, which was not representative enough and in which randomness existed. Furthermore, the balance between the two study groups was not fully compared, which may have led to a potential selection bias; 3) evidence of publication bias existed, suggesting that the higher RR may have come from few studies, which could have led to an overestimation of our pooled estimates. Thus, higher quality evidence in further studies is needed as a supplement to strengthen our confidence for a stronger recommendation.

We rated the evidence quality of NOS scores $\geq 7$ as "moderate", which meant we were moderately confident in the effect estimate and that the true effectiveness was likely to be close to the estimated effectiveness. It could be proven that the high-quality evidence or the strong recommendations need to be based on high-quality studies. Compared with the previous effectiveness estimate and quality assessment of the one-dose of varicella vaccine [39], which was studied relatively earlier, the studies included in this VE estimate were further improved in terms of information collection and presentation, case definition and exclusion, and paper writing.

However, we still found that the rating of the quality of some studies decreased due to information omission or inaccurate expression, rather than due to actual defects in methodology; this could likely explain why there was no significant difference in VE between studies in terms of NOS score-based quality. Therefore, it is suggested that technical guidelines must be formulated for observational studies in general, or even for observational studies on VE evaluation, including study design, data analysis, thesis writing, and other technical steps, to avoid the aforementioned problems for researchers and to improve the overall quality of evidence in China or on a global scale.

In addition to the aforementioned problems listed with the GRADE rating that affected the quality of evidence, our study still has several limitations. The relatively small number of study on two-dose varicella vaccine VE probably lead to the inaccurate evaluation of $\mathrm{VE}$, as one study apparently had a large sample size and higher RR that might have increased the estimated value. The majority of the studies did not provide enough data to allow for a more detailed analysis of the vaccine types (domestic vaccine or imported vaccine), disease severity, and age of subjects, all of which may have a potential effect on VE or the waning immunity related to the occurrence of breakthrough varicella. The approach of GRADE to rating quality of evidence has a great requirement for knowledge of researchers in related fields, and it cannot eliminate the subjective judgment of researchers [16]. However, based on the systematic and transparent manner of the evaluation, we reduced subjective influence through parallel evaluation by multiple researchers as much as possible.

\section{Conclusion}

Available data from China showed that the VE of the two-dose varicella vaccine is relatively high. To prevent varicella, it is recommended that the two-dose immunization strategy could be considered for countries 
that need to further control varicella, but higher-quality evidence is needed as a supplement for a stronger recommendation. The approach of GRADE could be applied to rating quality of evidence in observational studies of VE. It is necessary to formulate a technical guideline for observational studies to improve the quality of evidence.

\section{Abbreviations}

VE: Vaccine effectiveness; GRADE: Grades of Recommendation, Assessment, Development, and Evaluation; NOS: Newcastle Ottawa Scale; VZV: Varicellazoster virus; RR: Relative risk; Cl: Confidence interval

\section{Supplementary Information}

The online version contains supplementary material available at https:/doi. org/10.1186/s12879-021-06217-1

Additional file 1: Supplementary Table 1. Search strategies and Results of Literature Search by Database.

\section{Acknowledgements}

We would like to thank all the staff who had taken part in this study.

\section{Authors' contributions}

All authors have read and approved the manuscript. Zhujiazi Zhang: Dr. Zhang conceptualized the study, supervised data collection, carried out the initial analyses, interpreted results, drafted the manuscript, and submitted the final manuscript. Luodan Suo: Dr. Suo conceptualized the study, supervised data collection, carried out the initial analyses, interpreted results, reviewed the manuscript, and approved the final manuscript as submitted. Jingbin Pan: Dr. Pan conceptualized the study, supervised data collection, critically reviewed the manuscript, and approved the final manuscript as submitted. Dan Zhao: Dr. Zhao carried out data collection and the initial analyses and approved the final manuscript as submitted. Li Lu: Dr. Lu conceptualized the study, supervised data collection, interpreted the results, reviewed and revised the manuscript, and approved the final manuscript as submitted.

\section{Funding}

This research was supported by Beijing Natural Science Foundation (L202008) in study design, in the collection, analysis and interpretation of data and in writing the manuscript.

The datasets used and/or analyzed during the current study are available from the

corresponding author on reasonable request..

\section{Availability of data and materials}

Data sharing is not applicable to this article as no datasets were generated or analysed here. All of the articles included in this review are publicly available.

\section{Declarations}

Ethics approval and consent to participate

Not applicable.

\section{Consent for publication}

Not applicable.

\section{Competing interests}

The authors declare that they have no competing interests.

Received: 24 April 2020 Accepted: 20 May 2021

Published online: 09 June 2021

\section{References}

1. Arvin AM. Varicella-zoster virus. Clin Microbiol Rev. 1996;6(2):361-81. https:// doi.org/10.1136/adc.85.2.175a.
2. Nguyen $H Q$, Jumaan $A O$, Seward JF. Decline in mortality due to varicella after implementation of varicella vaccination in the United States. N Engl J Med. 2005;352(5):450-8. https://doi.org/10.1056/NEJMoa042271.

3. Streng A, Grote V, Carr D, Hagemann C, Liese JG. Varicella routine vaccination and the effects on varicella epidemiology -results from the Bavarian varicella surveinllance project (BaVariPro), 2006-2011. BMC Infect Dis. 2013;13(1):303. https://doi.org/10.1186/1471-2334-13-303.

4. Fu CX, Wang M, Liang J, Xu J, Wang C, Bialek S. The effectiveness of varicella vaccine in China. Pediatr Infect Dis J. 2010;29(8):19-23. https://doi. org/10.1097/INF.0b013e3181d7380e.

5. Lu L, Wang C, Suo L, Li J, Liu W, Pang X, et al. Varicella disease in Beijing in the era of voluntary vaccination, 2007 to 2010. Pediatr Infect Dis J. 2013; 32(8):e314-8. https://doi.org/10.1097//NF.0b013e31828d948b.

6. Lu L, Suo L, Li J, Zhai L, Zheng Q, Pang X, et al. A varicella outbreak in a school with high one-dose vaccination coverage, Beijing, China. Vaccine. 2012;30(34):5094-8. https://doi.org/10.1016/j.vaccine.2012.05.072.

7. Fu J, Wang J, Jiang C, Shi R, Ma T. Outbreak of varicella in a highly vaccinated preschool population. Int J Infect Dis. 2015;37:14-8. https://doi. org/10.1016/j.ijid.2015.06.003.

8. Kong DF, Tang XJ, et al. Analysis on epidemiological characteristics and vaccination of varicella in Shenzhen of Guangdong Province from 2013 to 2017. J Med Pest Control LiY. 2019;35(05):34-7. https://doi.org/10.7629/ yxdwfz201905008.

9. Beijing Center for Disease Control and Prevention. Beijing varicella vaccine recommendations. Chin J Prev Med. 2013;47(1). https://doi.org/10.3760/cma. j.issn.0253-9624.2013.01.016.

10. Zhao D, Suo L, Lu L, et al. Varicella vaccine coverage before and after recommending a two-dose varicella vaccination schedule in Beijing, 20072017. Chines J Vaccines Immunization. 2019;025(002):198-202.

11. Hu Y, Chen Y, Zhang B, Li Q. An evaluation of voluntary varicella vaccination coverage in Zhejiang Province, East China. Int J Environ Res Public Health. 2016;13(6):560. https://doi.org/10.3390/ijerph13060560.

12. Jinping WU, Mibo W. Two-dose varicella vaccination coverage among children born from 2008-2012 in Hengxi town, Ningbo. Pract Prev Med. 2017;24(6):712-5. https://doi.org/10.3969/j.issn.1006-3110.2017.06.021.

13. Chen JS, Lai QY, Lang WJ, et al. Study on the vaccine effectiveness of an outbreak of varicella in a primary school. South China J Prev Med. 2018; 44(04):58-60 04-014. CNKI:SUN:GDWF.0.

14. Zhuang $L$, Chen QX, Yi P. Epidemiological investigation on a varicella outbreak, Tongan district Xian city, 2018. Prev Med Tribune. 2019;7:510-3. https://doi.org/10.16406/j.pmt.issn.1672-9153.2019.07.010.

15. Atkins $D$, Eccles M, Flottorp $S$, et al. Systems for grading the quality of evidence and the strength of recommendations I: critical appraisal of existing approaches the GRADE working group. BMC Health Serv Res. 2004; 4(1):38. https://doi.org/10.1186/1472-6963-4-38.

16. Guyatt G, Oxman AD, Akl EA, Kunz R, Vist G, Brozek J, et al. GRADE guidelines: 1. Introduction-GRADE evidence profiles and summary of findings tables. J Clin Epidemiol. 2011;64(4):383-94. https://doi.org/10.1016/j. jclinepi.2010.04.026.

17. Schünemann HJ, Oxman AD, Brozek J, Glasziou P, Bossuyt P, Chang S, et al. GRADE: assessing the quality of evidence for diagnostic recommendations. Evid Based Med. 2008;13(6):162-3. https://doi.org/10.1136/ebm.13.6.162-a.

18. Schünemann $\mathrm{HJ}$, Fretheim $\mathrm{A}$, Oxman AD. Improving the use of research evidence in guideline development: 9 . Grading evidence and recommendations. Health Res Policy Syst. 2006:4(1):21. https://doi.org/10.11 86/1478-4505-4-21.

19. Yu HU, Ya-Ping C, Qian LI. Meta-analysis of vaccine protective efficacy of varicella attenuated live vaccine. Chin J Vaccines Immunization. 2011; 017(005):431-5.

20. Hong H, Wenqun C, Tianhan S. Meta-analysis of the effectiveness of varicella vaccine in outbreaks. Chinese J Vaccines Immunization. 2017:(03):331-6.

21. Yi Z, Jun-wei Z, Yin-Lan C, et al. Protective efficacy of varicella attenuated live vaccine for children in China:a Meta-analysis. Chin Prev Med. 2017; 018(008):587-92.

22. Vrabel M. Preferred reporting items for systematic reviews and metaanalyses. Oncol Nurs Forum. 2015;42(5):552-4. https://doi.org/10.1188/15. ONF.552-554.

23. Orenstein WA, Bernier RH, Dondero TJ, Hinman AR, Marks JS, Bart KJ, et al. Field evaluation of vaccine efficacy. Bull World Health Organ. 1985;63(6): 1055-68. 
24. Orenstein WA, Bernier RH, Hinman AR. Assessing vaccine efficacy in the field. Further observations. Epidemiol Rev. 1988;10(1):212-41. https://doi. org/10.1093/oxfordjournals.epirev.a036023.

25. Stang A. Critical evaluation of the Newcastle-Ottawa scale for the assessment of the quality of nonrandomized studies in meta-analyses. Eur J Epidemiol. 2010;25(9):603-5. https://doi.org/10.1007/s10654-010-9491-z.

26. Wells GA, Shea B, O'Connell D, et al. The Newcastle-Ottawa Scale (NOS) for assessing the quality of nonrandomized studies in meta-analyses [EB/OL], 2012-06-15. http://www.ohri.ca/programs/clinical_epidemiology/oxford.htm

27. Deeks J, Higgins J, Altman D. Analyzing data and undertaking meta-analyses Cochrane handbook for systematic reviews of interventions: Cochrane Book Series Wiley-Blackwell; 2008. https://doi.org/10.1002/9780470712184.ch9.

28. Balshem $H$, Helfand $M$, Schünemann $H J$, Oxman AD, Kunz R, Brozek J, et al. GRADE guidelines. GRADE guidelines: 3. Rating the quality of evidence. J Clin Epidemiol. 2011;64(4):401-6. https://doi.org/10.1016/j.jclinepi.2010.07.01 5.

29. Pang $H$, Wang $C$, Jiang $Y$, et al. Comparison of varicella vaccine effectiveness during outbreak in a primary school. Chin J Biol. 2015;28(1):68-71.

30. Sui HT, Yao JY, Lin QZ, et al. Field investigation of a varicella outbreak in a primary School of Zhangpu County, Fujian Province, 2015. Chin J Vaccines Immunization. 2016;022(006):642-5 615. DOI:CNKI:SUN:ZGJM.0.2016-06-009.

31. Zhu Q, Wang XX, Su WC, et al. Effectiveness of varicella vaccine based on several varicella outbreaks in Guangdong Province. South China J Prev Med. 2016;2:129-33. https://doi.org/10.13217/j.scjpm.2016.0129.

32. Wei YJ. An outbreak of breakout varicella in a primary school in Xicheng District, Beijing. Chin J School Health. 2017;3. https://doi.org/10.16835/j. cnki.1000-9817.2017.03.048

33. Pan $X$, Shu M, Ma R, Fang T, Dong $H$, Sun $Y$, et al. Varicella breakthrough infection and effectiveness of 2-dose varicella vaccine in China. Vaccine. 2018;36(37):5665-70. https://doi.org/10.1016/j.vaccine.2018.05.025.

34. Sun Y, Wang DM, Cui WH, et al. An outbreak of varicella among students in an urban primary school in Yantai city of Shandong Province, 2016. Chin J Vaccines Immunization. 2017;04-016(04):70-3 + 80. DOI:CNKI:SUN:ZGJM.0.

35. Xu W, Luodan S, Qing W, et al. Investigation of a varicella outbreak in a primary school after implementation of the 2-doses immunization strategy in Beijing. Int J Virol. 2017;24(5):318-21. https://doi.org/10.3760/cma.j.issn.1 673-4092.2017.05.007.

36. Cai JT, Wang YX. Analysis on the effectiveness of varicella vaccine for preventing varicella [J]. China Health Care Nutr. 2017;27(34):295. https://doi. org/10.3969/j.issn.1004-7484.2017.34.445[37].

37. Ni ZR, Zhang XM, Pan QJ, et al. Evaluation of vaccine effectiveness of an outbreak of varicella in primary school in Wenzhou. Chin J School Health. 2018;(8):1268-70. https://doi.org/10.16835/j.cnki.1000-9817.2018.08.047[38.

38. Marin M, Marti M, Kambhampati A, Jeram SM, Seward JF. Global varicella vaccine effectiveness: A meta-analysis. Pediatrics. 2016;137(3):e20153741. https://doi.org/10.1542/peds.2015-3741.

39. Zhang ZJZ, Suo LD, Zhao D, Pan JB, Lu L. Systematic reviews and evidence quality assessment on effectiveness of 1 dose varicella attenuated live vaccine for healthy children aged 1-12 years in China. Chin J Epidemiol. 2020;41(7):1138-44. https://doi.org/10.3760/cma.j.cn112338-20191025-00762.

40. Belongia EA, Simpson MD, King JP, Sundaram ME, Kelley NS, Osterholm MT, et al. Variable influenza vaccine effectiveness by subtype: a systematic review and meta-analysis of test-negative design studies. Lancet Infect Dis. 2016;16(8):942-51. https://doi.org/10.1016/S1473-3099(16)00129-8.

41. de Oliveira LH, Camacho LA, Coutinho ES, et al. Rotavirus vaccine effectiveness in Latin American and Caribbean countries: a systematic review and meta-analysis. Vaccine, 2015, 33 Supplement 1:A248-A254. DOI: https://doi.org/10.1016/j.vaccine.2014.11.060

42. King GE, Markowitz LE, Patriarca PA, et al. Clinical efficacy of measles vaccine during the 1990 measles epidemic. Pediatr Infect Dis J. 1991;10(12):883-8. https://doi.org/10.1097/00006454-199112000-00001.

43. Marin M, Nguyen HQ, Langidrik JR, Edwards R, Briand K, Papania MJ, et al. Measles transmission and vaccine effectiveness during a large outbreak on a densely populated island: implications for vaccination policy. Clin Infect Dis. 2006;42(3):315-9. https://doi.org/10.1086/498902.

44. Chang $\mathrm{C}, \mathrm{Mo} X, \mathrm{Hu}$ P, Liang W, Ma H, An Z, et al. Effectiveness of rubella vaccine in a rubella outbreak in Guangzhou city, China, 2014. Vaccine. 2015; 33(28):3223-7. https://doi.org/10.1016/j.vaccine.2015.04.083.

45. Suo L, Li J, Zhao D, Yang F, Liu W, Wu J, et al. Effect evaluation of a 2 dose varicella vaccine immunization strategy implemented to control outbreaks in school and kindergarten settings. Zhonghua Yu Fang Yi Xue za Zhi. 2015; 49(6):485-9. https://doi.org/10.3760/cma.j.issn.0253-9624.2015.06.006.

46. Thomas CA, Shwe T, Bixler D, del Rosario M, Grytdal S, Wang C, et al. Twodose varicella vaccine effectiveness and rash severity in outbreaks of varicella among public school students. Pediatr Infect Dis J. 2014;33(11): 1164-8. https://doi.org/10.1097/INF.0000000000000444.

47. Shapiro ED, Vazquez M, Esposito D, Holabird N, Steinberg SP, Dziura J, et al. Effectiveness of 2 doses of varicella vaccine in children. J Infect Dis. 2011; 203(3):312-5. https://doi.org/10.1093/infdis/jiq052.

48. Fine PEM, Zell ER, Elizabeth R. Zell. Outbreaks in highly vaccinated populations: implications for studies of vaccine performance. Am J Epidemiol. 1994;139(1):77-90. https://doi.org/10.1093/oxfordjournals.aje.a11 6937.

49. Guyatt GH, Oxman AD, Sultan S, Glasziou P, Akl EA, Alonso-Coello P, et al. GRADE guidelines. GRADE guidelines: 9. Rating up the quality of evidence. J Clin Epidemiol. 2011;64(12):1311-6. https://doi.org/10.1016/j.jclinepi.2011.06. 004.

\section{Publisher's Note}

Springer Nature remains neutral with regard to jurisdictional claims in published maps and institutional affiliations.

\section{Ready to submit your research? Choose BMC and benefit from:}

- fast, convenient online submission

- thorough peer review by experienced researchers in your field

- rapid publication on acceptance

- support for research data, including large and complex data types

- gold Open Access which fosters wider collaboration and increased citations

- maximum visibility for your research: over $100 \mathrm{M}$ website views per year

At BMC, research is always in progress.

Learn more biomedcentral.com/submissions 